\title{
Entire Collection
}

\section{0 lines, 592 mapped DArTs (10\% cutoff)}
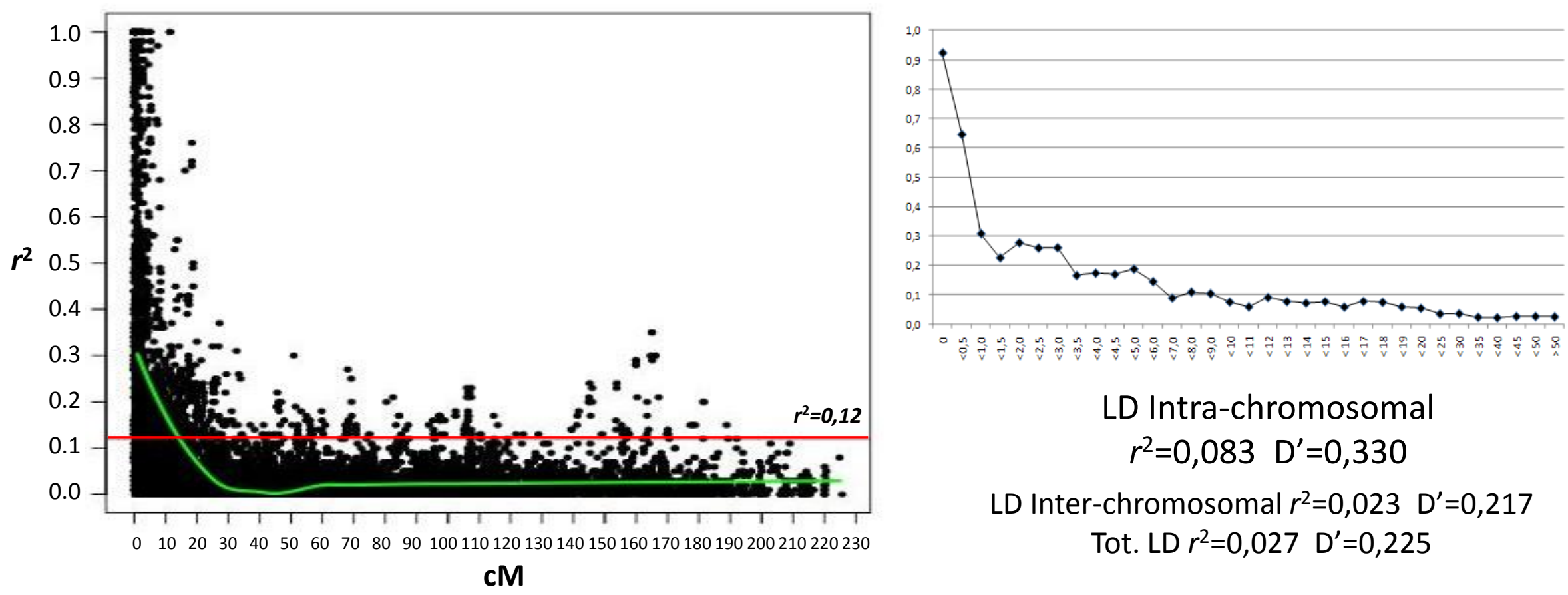

LD Inter-chromosomal $r^{2}=0,023 \quad D^{\prime}=0,217$

Tot. $\operatorname{LD} r^{2}=0,027 \quad D^{\prime}=0,225$

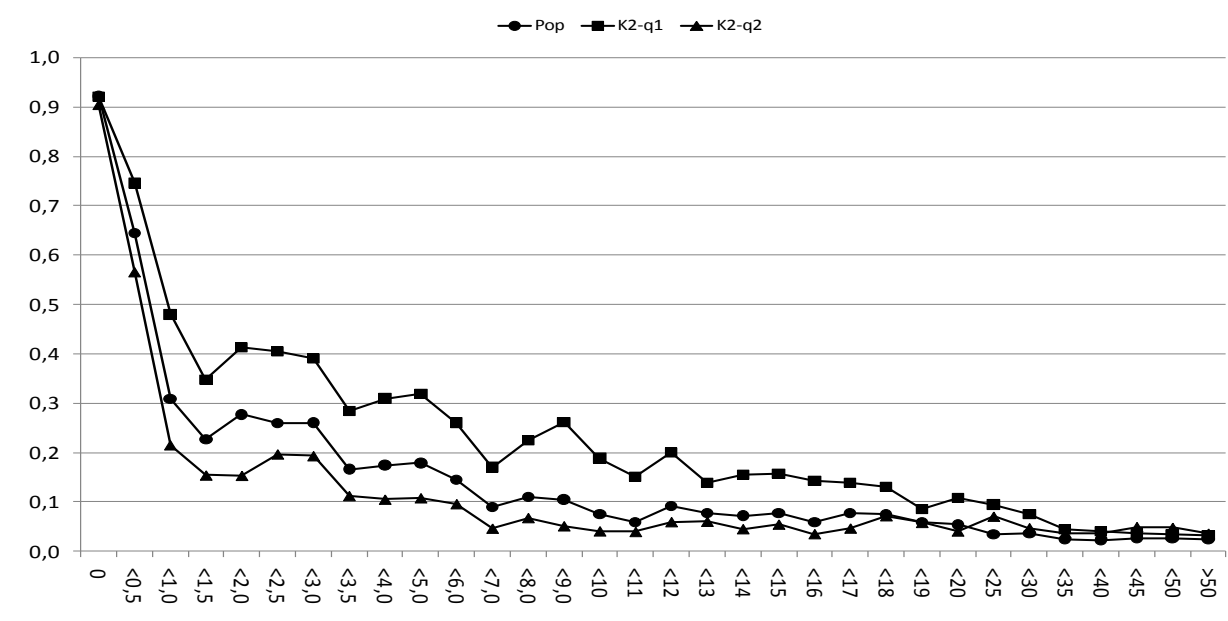

In the entire collection under investigation 5,066 (41.2\%) of the 12,301 intrachromosomal marker pairs showed a significant level of $\operatorname{LD}(P<0,01)$.

The average of $r^{2}$ for all pairs was 0.083 . 


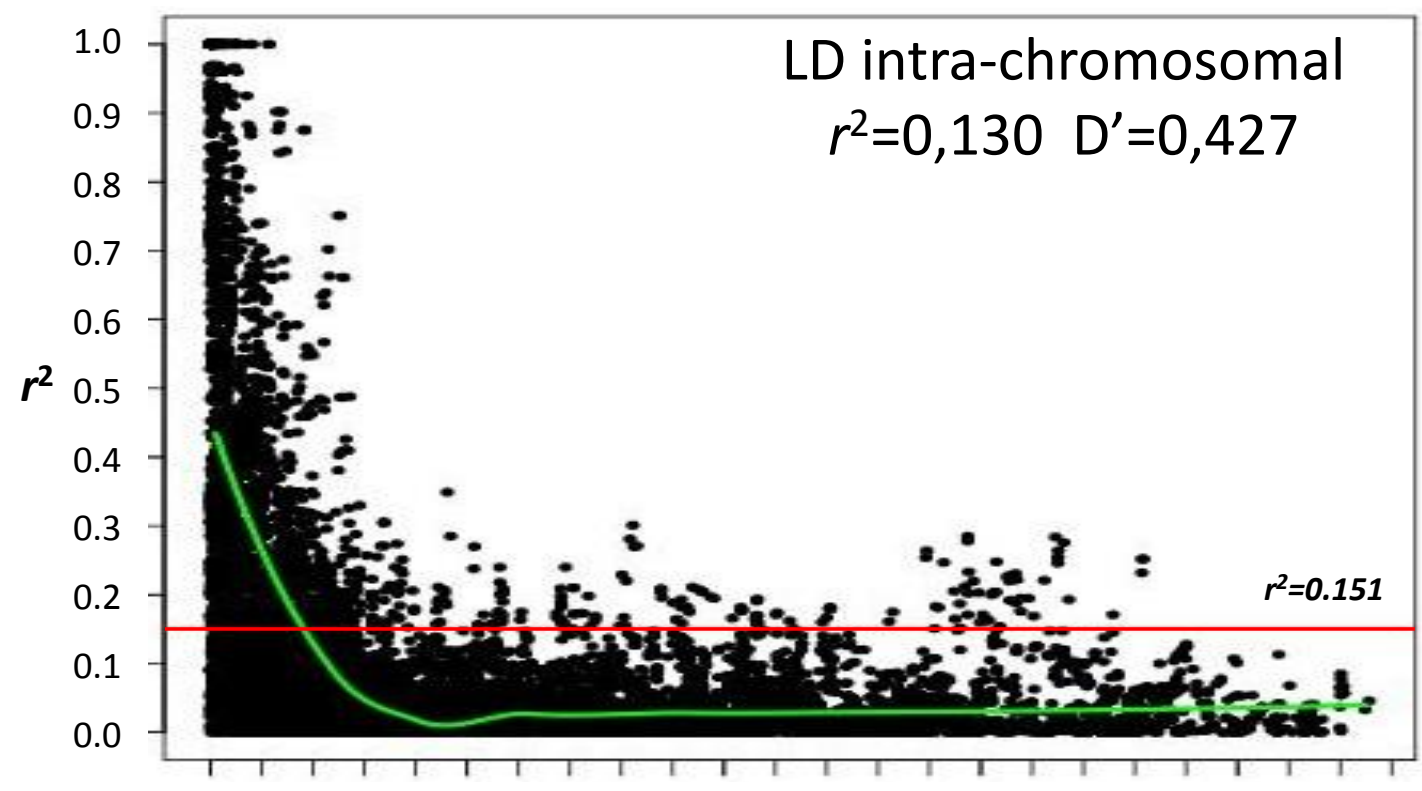

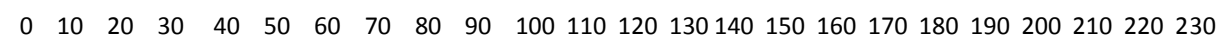
CM

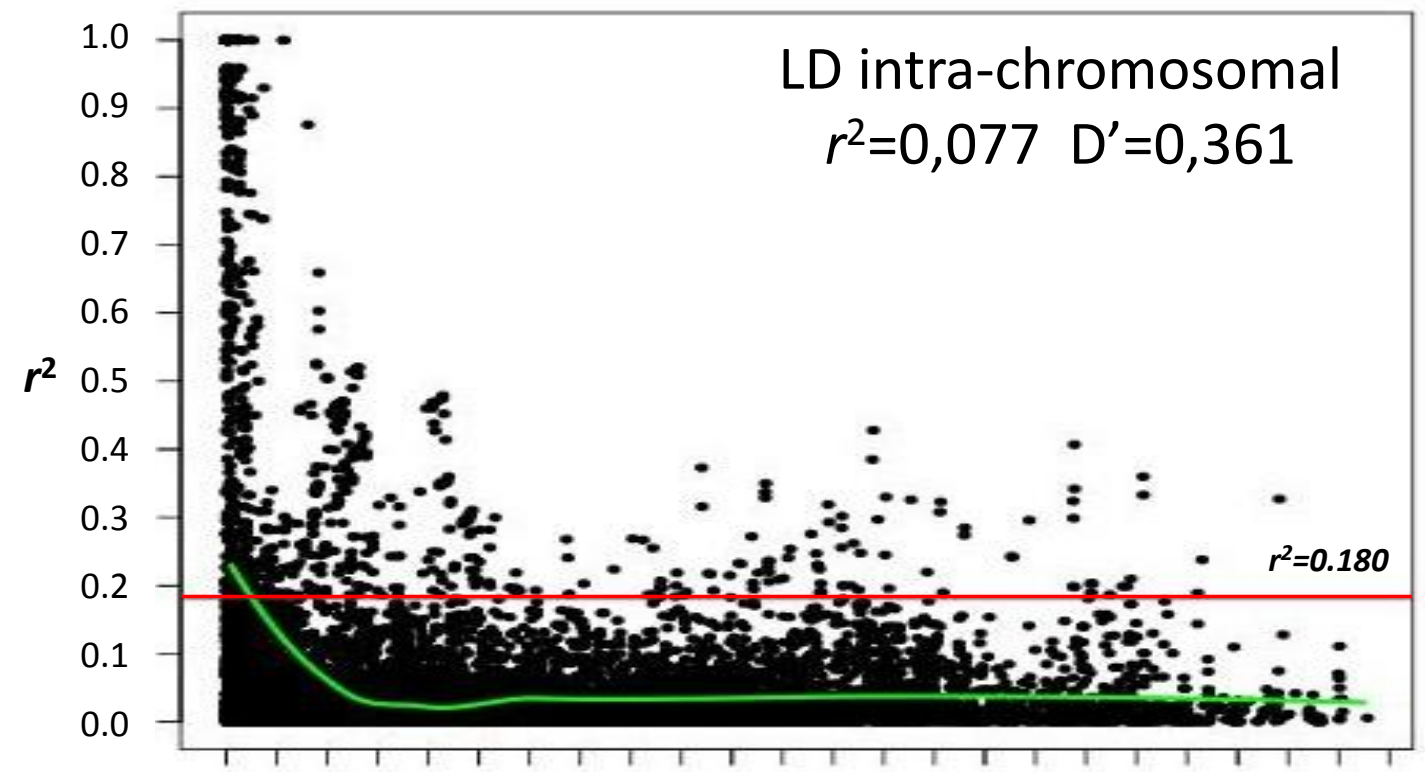

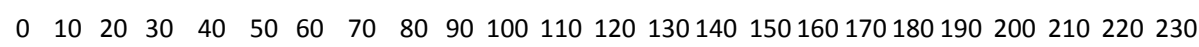
cM $1^{\circ}$ Sub-Group (SSR Structure) 129 lines, 577 mapped DArTs (10\% cutoff)

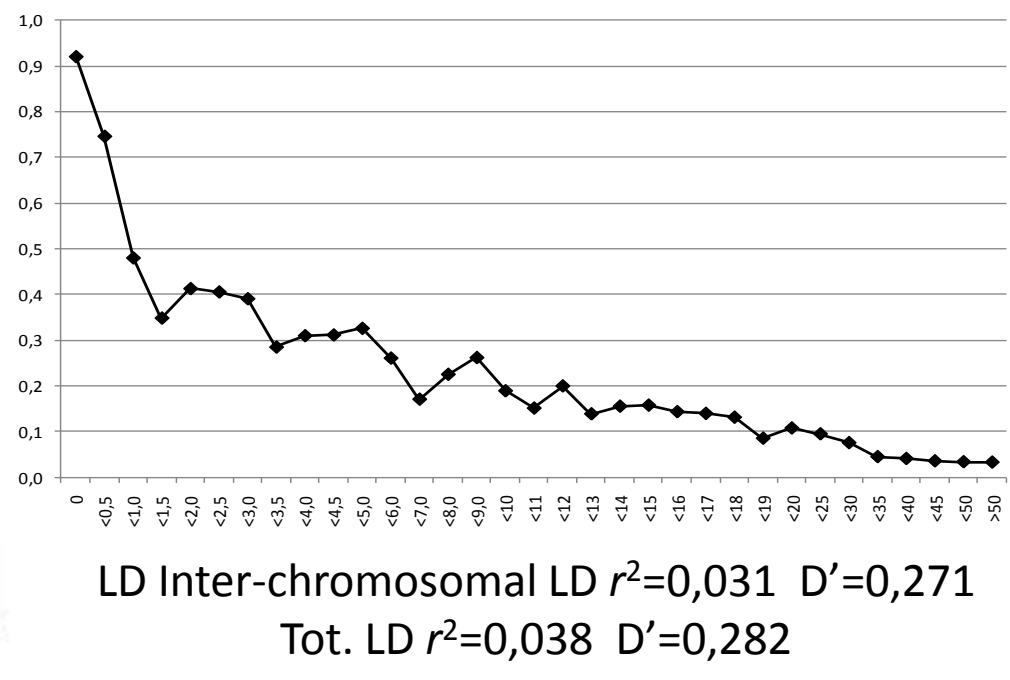

\section{$2^{\circ}$ Sub-Group (SSR Structure)}

101 lines, 565 mapped DArTs (10\% cutoff)

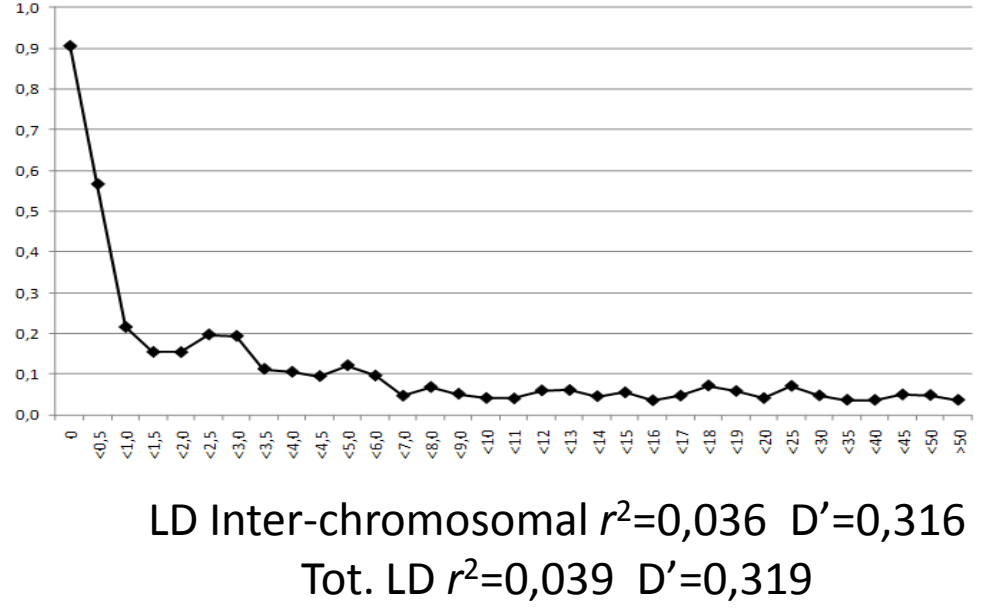




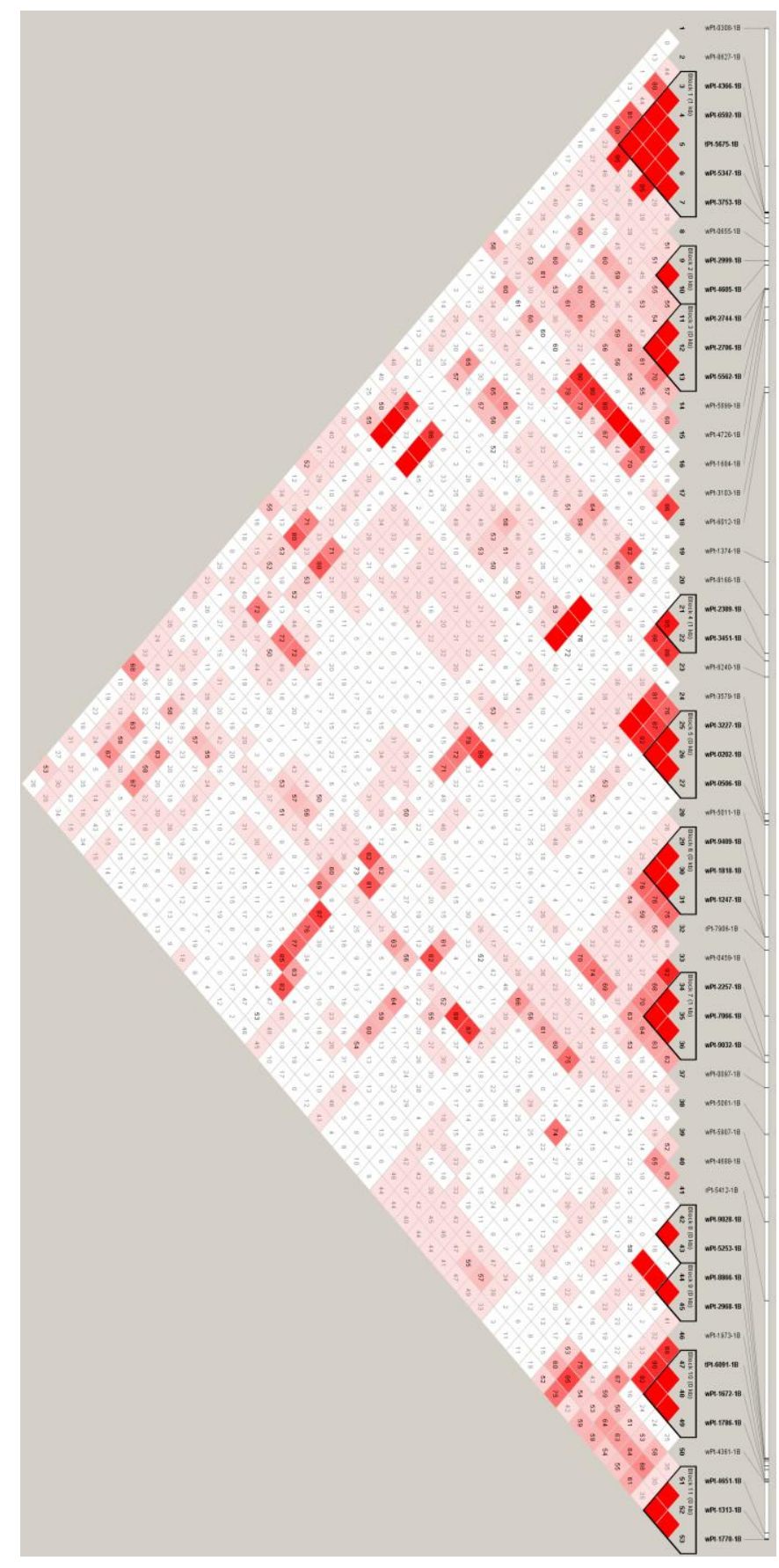

\section{Cromosoma 1B}

LD Intra-chromosomal $r^{2}=0,06 D^{\prime}=0,290$ $\mathrm{N}^{\circ}$ pairs 1378 (53 DArT markers)

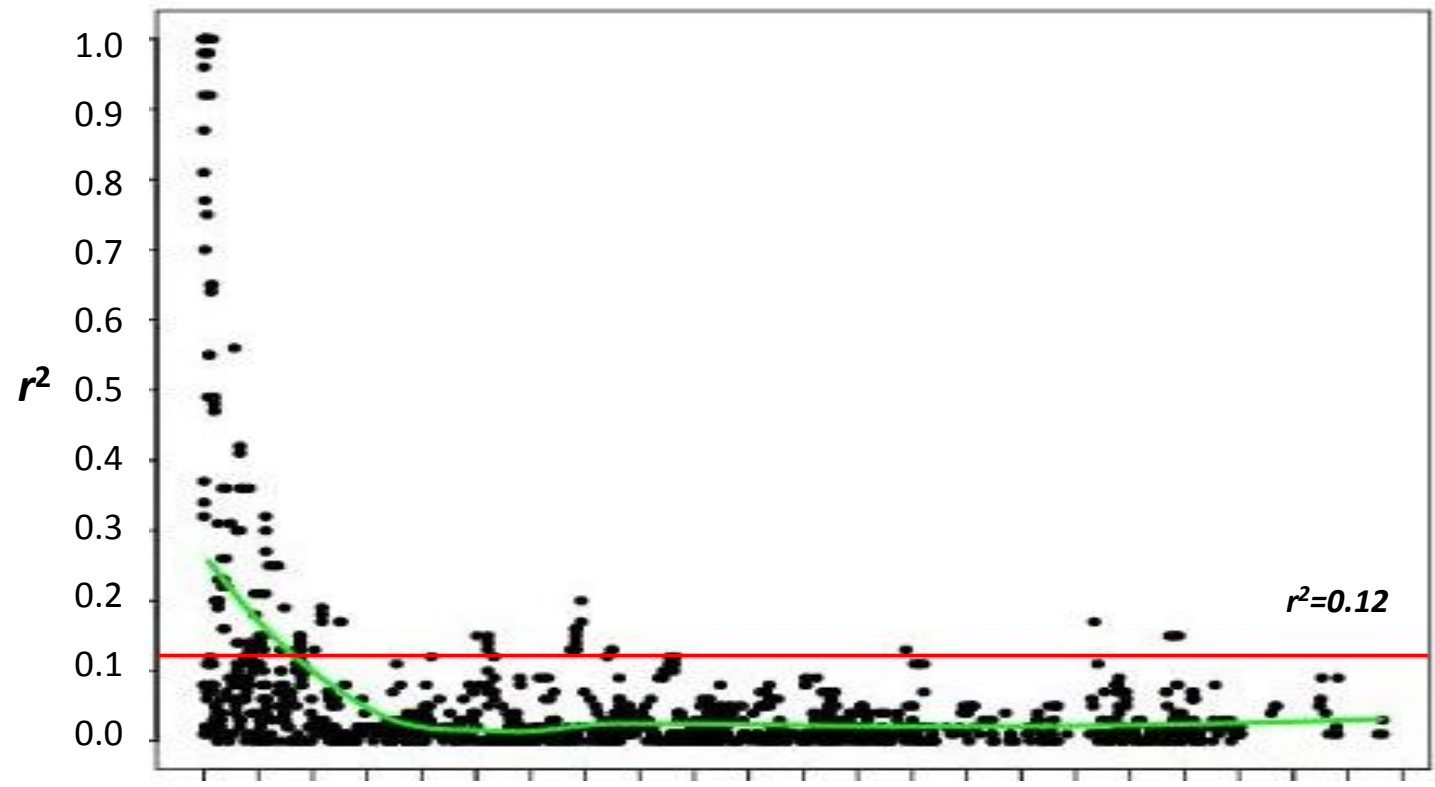

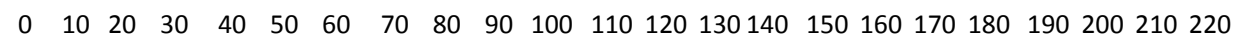
cM

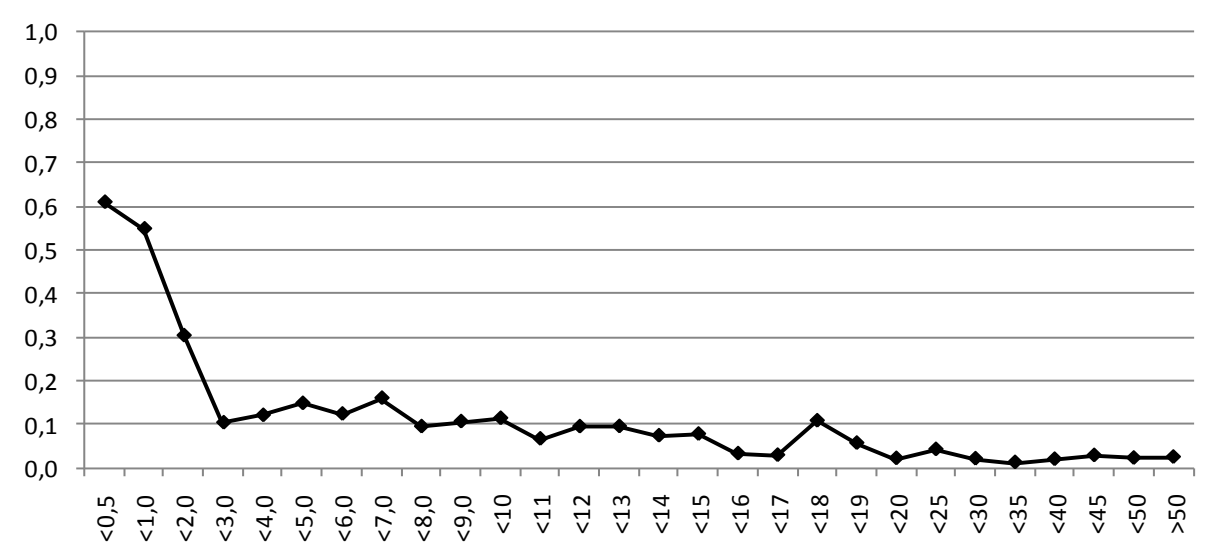




\section{Cromosoma 3B-2}

Mean intra-chromosomal LD $r^{2}=0,17$ and $D^{\prime}=0,430$ $\mathrm{N}^{\circ}$ pairs 351 (27 DArT markers)
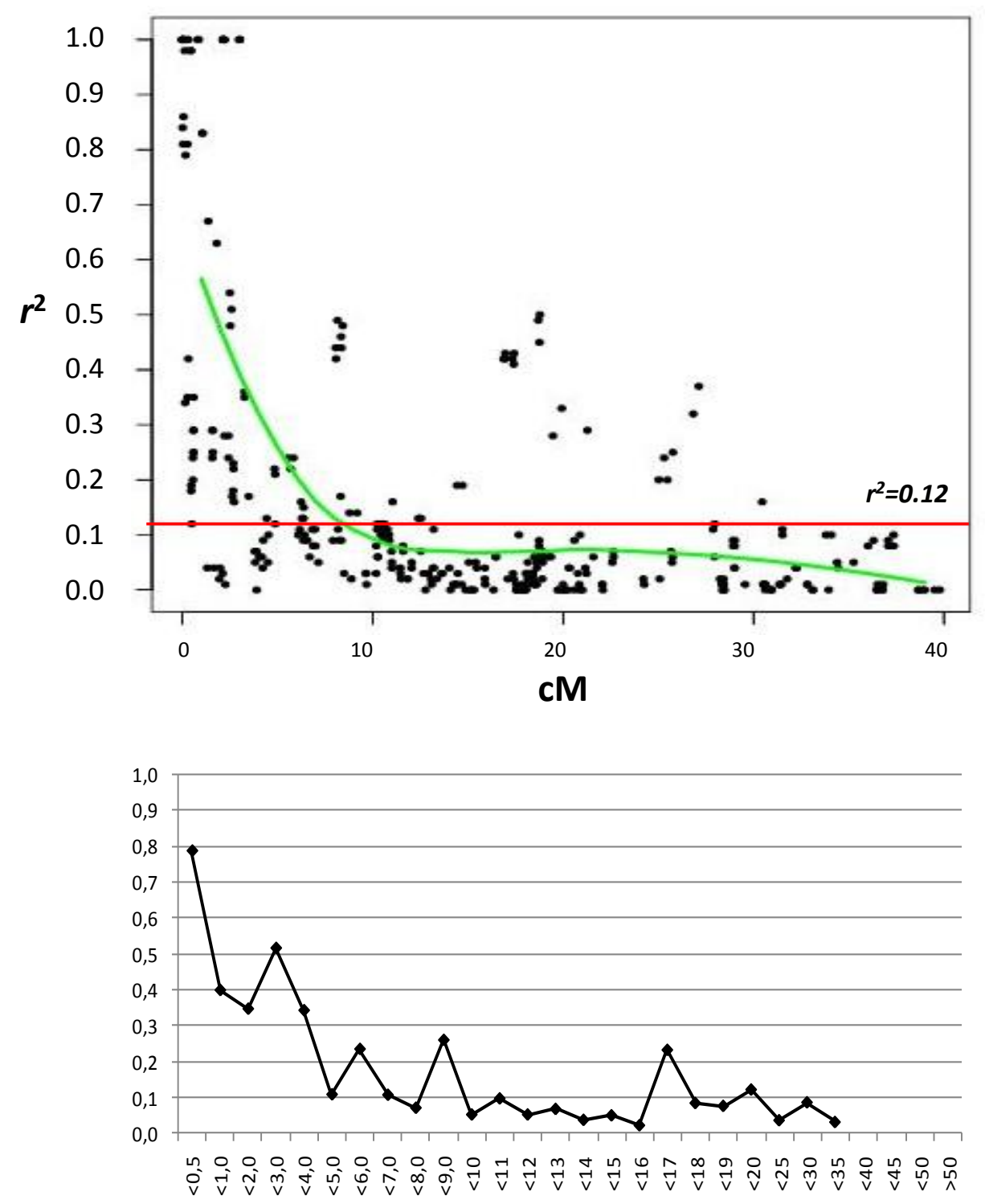


\section{Cromosoma 4A}

Mean intra-chromosomal LD

$r^{2}=0,07$ and $D^{\prime}=0,360$

$\mathrm{N}^{\circ}$ pairs 1596 (57 DArT markers)
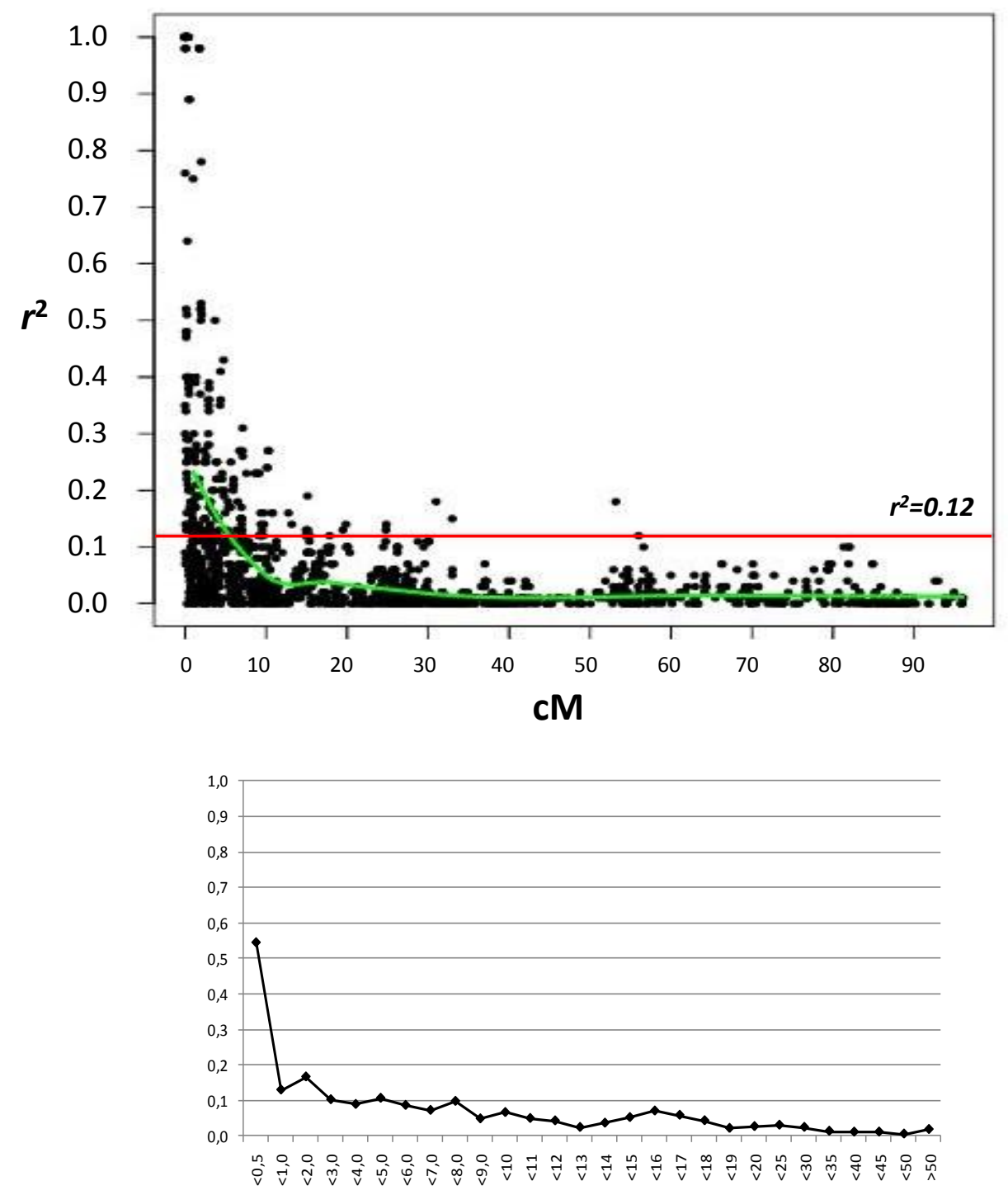


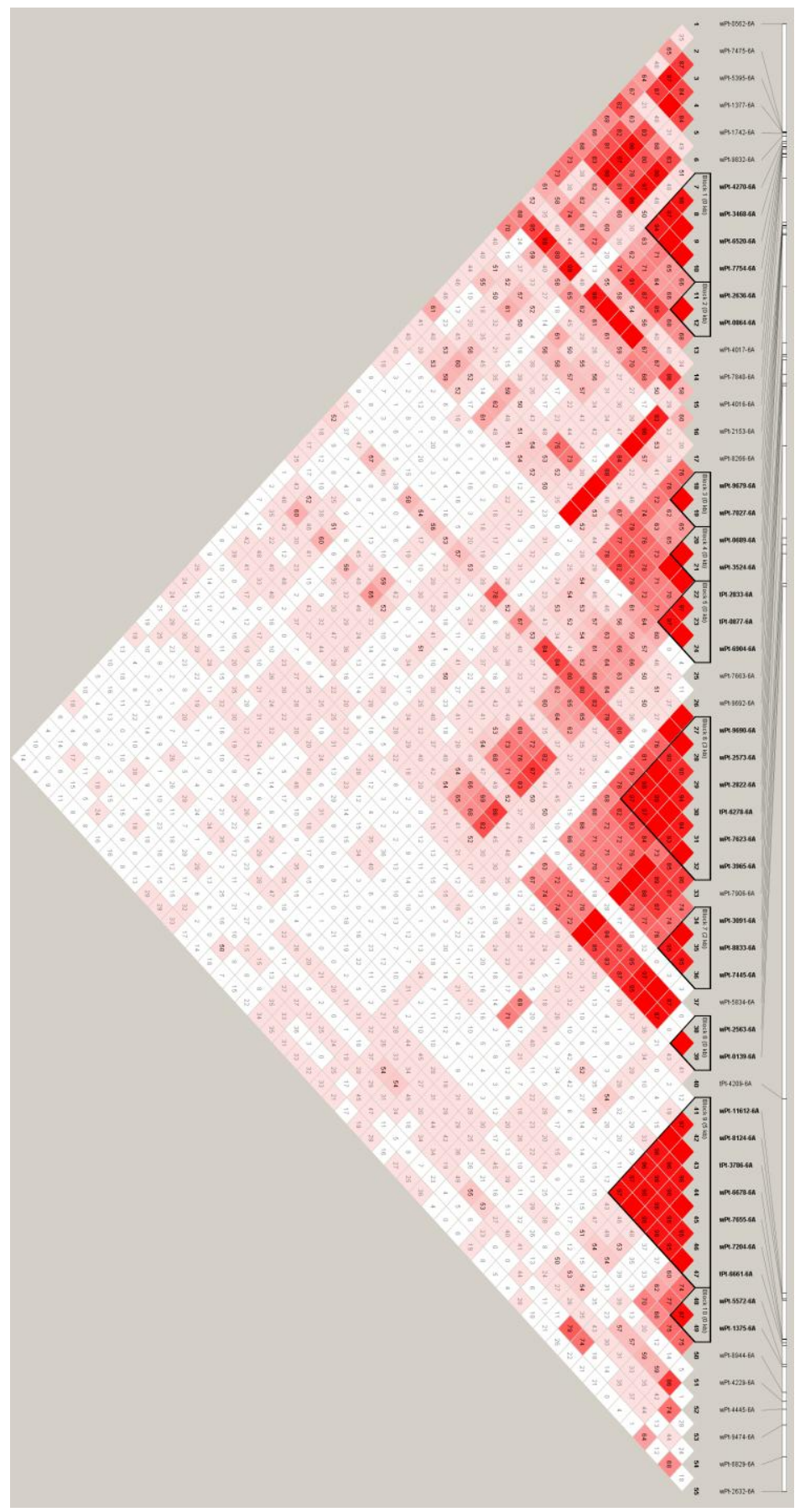

\section{Cromosoma 6A}

Mean intra-chromosomal LD

$r^{2}=0,11$ and $D^{\prime}=0,340$

$\mathrm{N}^{\circ}$ pairs 1486 (55 DArT markers)
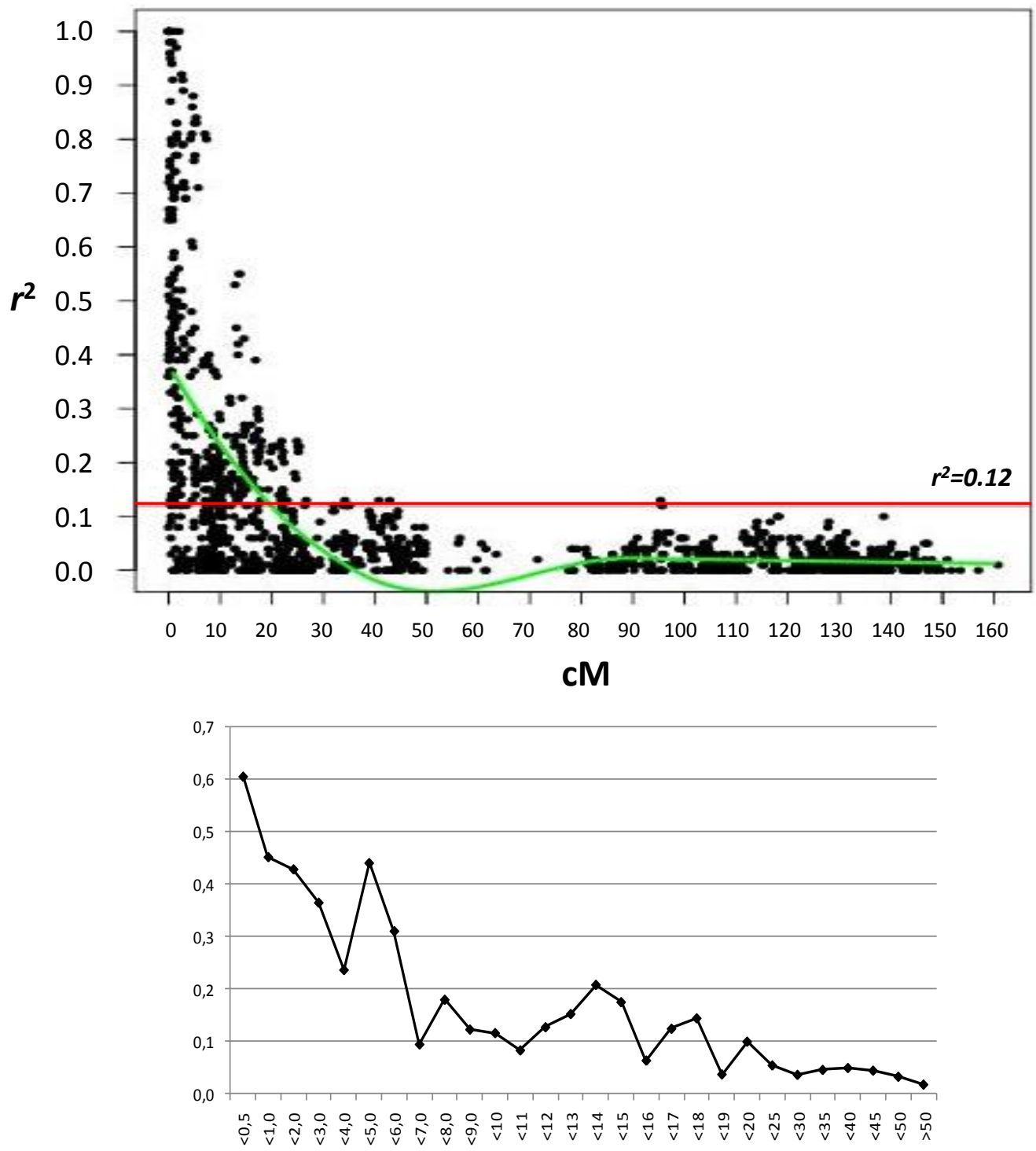


\section{Cromosoma 6B}

Mean intra-chromosomal LD

$r^{2}=0,06$ and $D^{\prime}=0,290$

$\mathrm{N}^{\circ}$ pairs 1769 (60 DArT markers)
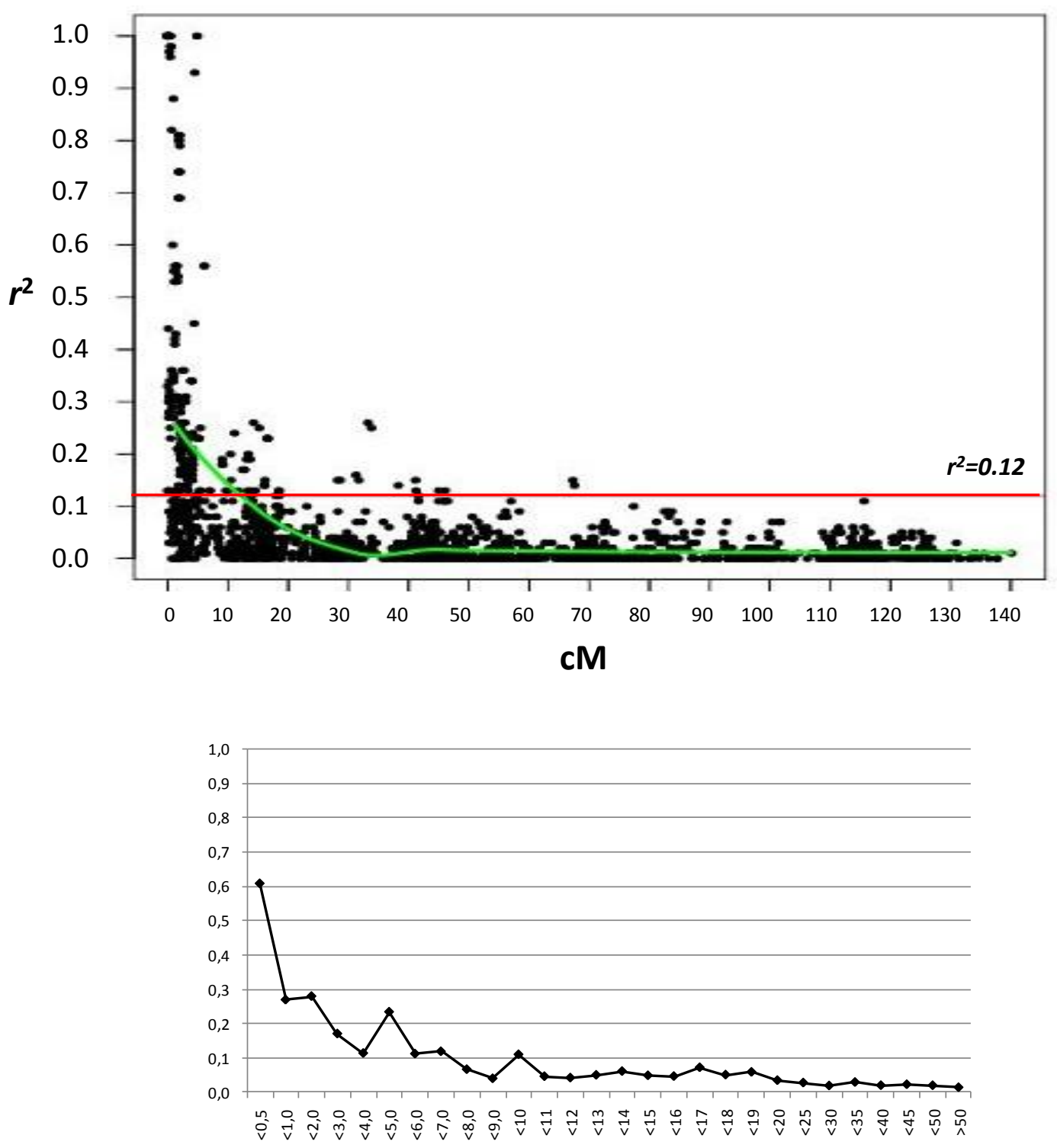


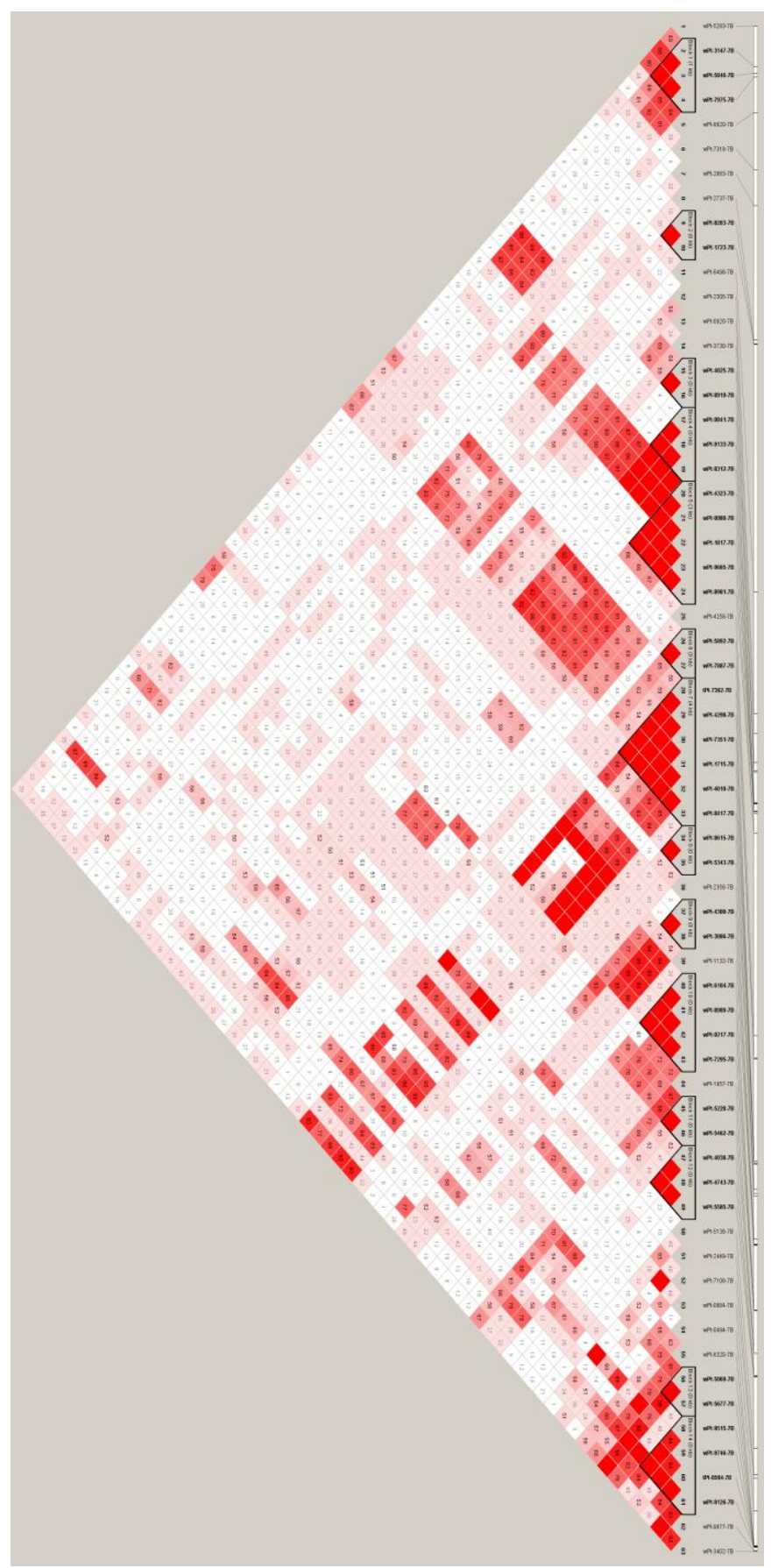

\section{Cromosoma 7B}

Mean intra-chromosomal LD

$r^{2}=0,06$ and $D^{\prime}=0,340$

$N^{\circ}$ pairs 1953 (63 DArT markers)

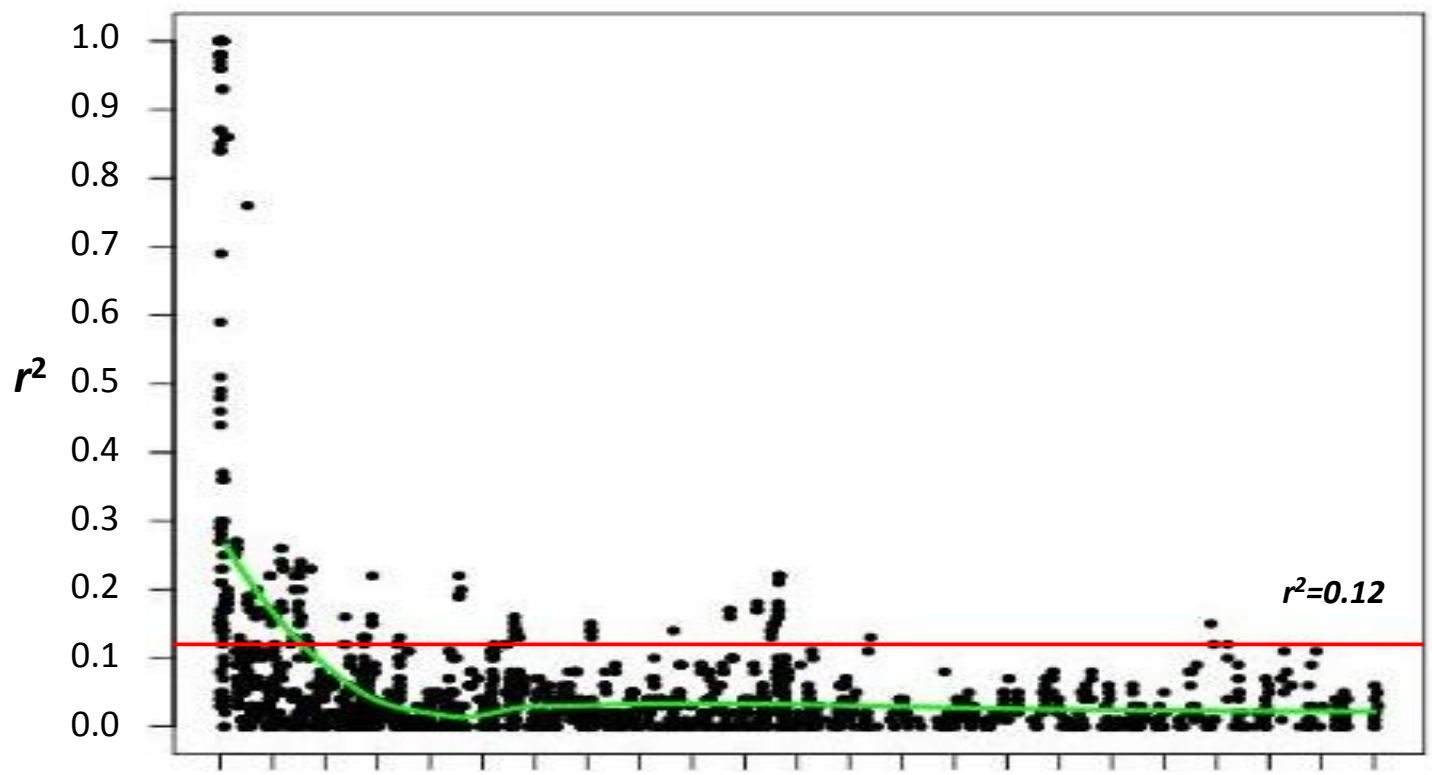

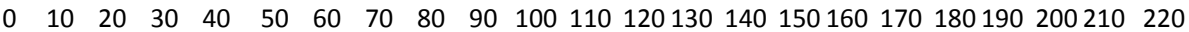
cM

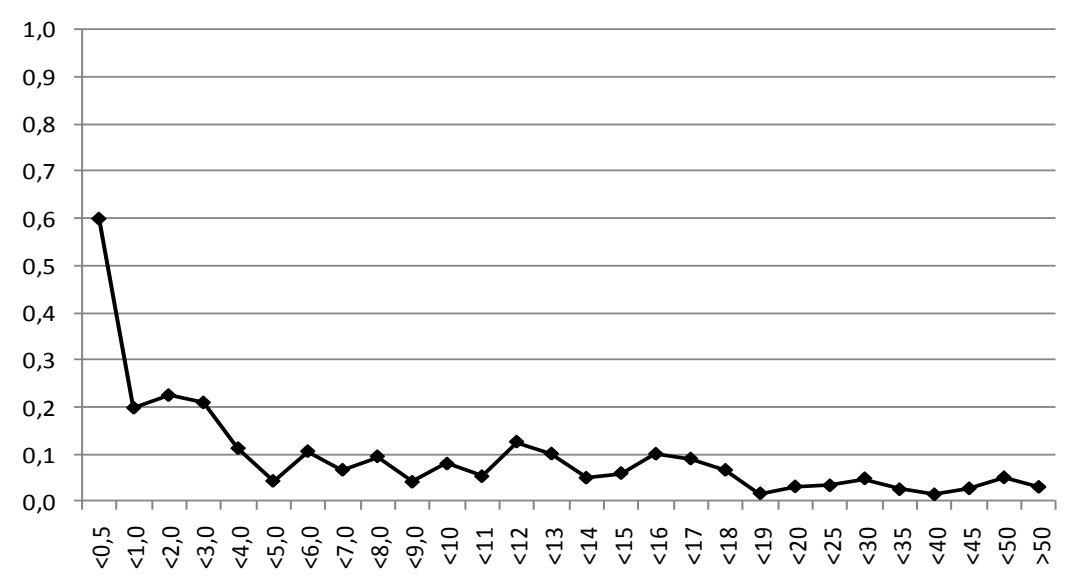

